\title{
USOS DA PROPRIEDADE RURAL E A NOVA LEGISLAÇÃO AMBIENTAL NO MUNICÍPIO DE PELOTAS, RS: UMA CONCILIAÇÃO VIÁVEL?
}

\author{
Letícia Bauer Nino ${ }^{1}$ \\ Flávio Sacco dos Anjos ${ }^{2}$
}

\begin{abstract}
RESUMO
O direito de propriedade rural sofreu transformações importantes ao longo do tempo no Brasil. A instituição do conceito de função social da terra e, mais recentemente, a função ambiental dos recursos naturais tem incidido fortemente ao questionar a concepção absoluta e individualista que se impôs, durante muito tempo, sobre a sociedade em geral. Este trabalho centrou-se em algumas indagações centrais, a saber: Como se apresentam as representações sociais dos atores sociais do município de Pelotas/RS sobre o uso dos recursos naturais, em que pese a emergência de um novo marco jurídico que regula as atividades agropecuárias, em meio aos objetivos conservacionistas ou da sustentabilidade ambiental? Por outro lado, cabe indagar: é possível conciliar os interesses dos produtores, suas práticas e representações sociais sobre a propriedade e uso racional dos recursos produtivos com o esforço da sociedade em preservar a integridade dos ecossistemas? Para responder o problema de pesquisa, desenvolveu-se uma pesquisa qualitativa, na qual foram realizadas onze entrevistas individuais semi-estruturadas. As percepções dos atores sociais ouvidos expressam a realidade do setor agropecuário e um ambiente real de incertezas. A análise do conteúdo das entrevistas revelou também que o conflito, ainda claramente perceptível entre as diferentes posições, está passando por um processo de ajustamento, seja através da adaptação à legislação ambiental e das exigências da sustentabilidade quanto às práticas sociais, seja no sentido da adoção de novas posturas e superação frente à concepção patrimonialista que marca a história brasileira.
\end{abstract}

Palavras-chave: análise de conteúdo, representações sociais.

\footnotetext{
${ }^{1}$ Mestre em Ciências Sociais pela Universidade Federal de Pelotas e Doutoranda no Programa de PósGraduação em Sistemas de Produção Agrícola Familiar da Universidade Federal de Pelotas.

${ }^{2}$ Doutor em Sociologia, Professor do Programa de Pós-Graduação em Sistemas de Produção Agrícola Familiar e do Mestrado em Ciências Sociais da Universidade Federal de Pelotas, Bolsista de Produtividade 2do CNPq.
} 


\title{
THE RURAL PROPERTIES AND THE NEW ENVIRONMENTAL LEGISLATION IN PELOTAS-RS: A VIABLE CONCILIATION?
}

\begin{abstract}
The right to land ownership has been under important changes in Brazil. The concept of the land function in society and, more recently, the environmental function of natural resources has strongly focused to question the absolute and individualistic concept which has been prevailing about society in general. This work questioned: How are presented the social representations of social actors in the municipality of Pelotas, Brazil regarding the use of natural resources under a new legal framework which regulates agricultural activities between the conservation objectives and environmental sustainability? On the other hand: is it possible to conciliate the interests of producers, their practices and social representations of property and rational use of productive resources with the company's efforts to preserve the integrity of ecosystems? A qualitative research was carried out to answer the research question, which was held eleven semi-structured individual interviews. The social actors were heard and their perceptions express the reality of the agricultural sector and as well a real uncertainty environment. An analysis of the interviews also showed a clearly perceptible conflict, among the different positions, which has been through a process of adjustment, either through the adaptation to environmental legislation and the requirements of sustainability as social practices or the sense of adopting new attitudes and overcoming the patrimonial conception which marks Brazilian history.
\end{abstract}

Key words: content analysis, social representations.

\section{INTRODUÇÃO}

Foi na Constituição Brasileira de 1934 que surgiu a discussão sobre o princípio da função social da terra. Posteriormente, durante o regime militar, houve a implantação do Estatuto da Terra (Lei 4504 de 30-11-64), cuja aplicação ficou absolutamente engessada em face dos efeitos do regime autoritário. Com a Constituição Brasileira de 1988, retorna o Estado democrático de direito e a discussão sobre o tema volta à cena. Desde então o direito de propriedade vem sofrendo novas transformações, visando a atender a novas finalidades, principalmente no que afeta à preservação dos recursos naturais para as futuras gerações.

De uma concepção individualista do uso da propriedade, passou-se, além do atendimento da sua função social, à busca por afirmar a sua função ambiental, em que pese a ênfase dos interesses coletivos sobre os individuais. Sabidamente, as novas teses que propugnam o "desenvolvimento sustentável" nem sempre foram acolhidas com entusiasmo pelos proprietários rurais, especialmente quando se traduzem no estabelecimento de limites ao exercício do uso dos recursos produtivos.

Enquanto que até meados do século passado o proprietário da terra tendia a encastelar-se na defesa de suas prerrogativas de dono absoluto, mais recentemente, com a percepção dos riscos reais de esgotamento da capacidade de renovação dos recursos naturais, essa situação se modifica. Muitos setores da sociedade se mobilizam em favor da proteção dos ecossistemas, fato que repercute 
sobre a noção de privilégios exclusivos de domínio, vistos por muitos como uma das principais causas da exploração desmedida dos recursos.

As tensões entre órgãos de fiscalização e proprietários rurais foram recorrentes nas três últimas décadas. Em boa medida, representam o reflexo de um conflito entre duas grandes concepções. A primeira delas, tradicional e patrimonialista, é pautada no exercício pleno do uso do domínio. A segunda, ainda em fase de consolidação, defende limites ao uso dos recursos naturais. Mas não se trata simplesmente de um embate entre ambientalistas e ruralistas, como se costuma afirmar, mas entre visões de mundo muito distintas.

Neste artigo analisamos esse tema a partir de uma perspectiva sócioantropológica. Entendemos que as práticas e orientações dos atores sociais podem ser analisadas a partir das representações sociais, entendidas aqui como processos mentais compartilhados. Por outro lado, suas lógicas são governadas pelo que se conhece como habitus ${ }^{3}$. Determinadas práticas dos atores, sob a influência do habitus, serão constrangidas por estruturas sociais, mas também, as ações dos indivíduos irão reproduzir e atualizar as estruturas sociais.

Sendo assim, o trabalho proposto tem como objetivo geral analisar as representações sociais de atores sociais com relação ao direito de propriedade da terra e do uso dos recursos naturais, tendo em vista as disposições que emanam do novo Código Florestal, que passou a regular as atividades agropecuárias. Este foi inspirado nos princípios da sustentabilidade, preservação dos recursos naturais e usos não exclusivamente centrados na produção agropecuária.

A próxima seção do artigo é dedicada a uma breve discussão sobre o direito de propriedade, ao passo que a terceira e quarta analisam, respectivamente, a função social e a função ambiental da propriedade da terra, incluindo a questão dos espaços territoriais especialmente protegidos, e a polêmica em torno da alteração do código florestal. Na quinta seção tratamos do método utilizado na realização da pesquisa, enquanto a sexta analisa e discute os resultados.

\section{DIREITO DE PROPRIEDADE}

Nos primórdios da humanidade, o domínio da terra era fundamentalmente uma noção ligada à ordem natural, vaga e imprecisa, até que se chegou à ideia atual de propriedade com um significado jurídico e, principalmente, econômico. A apropriação da terra como ato dos indivíduos apenas ocorrerá quando a força e a violência estiverem autorregulamentadas na forma de poder organizado, instituindose, portanto, como direito (VIAL, 2003). Para que se chegue à concepção atual sobre a propriedade da terra no Brasil, é preciso que se busquem alguns subsídios históricos que indiquem como se deu a evolução social no que tange à ocupação, conquista e posse da propriedade.

O domínio do continente latino-americano já era objeto de disputa entre as duas coroas ibéricas, muito antes das "descobertas". Estabelecido em 1493, o Tratado de Tordesilhas divide o novo mundo em duas grandes áreas a serem conquistadas pelos reinos de Portugal e Espanha. Posteriormente, em 1534, para promover o povoamento efetivo e o desenvolvimento da colônia portuguesa na América, o rei D. João III instituiu o sistema das Capitanias Hereditárias, que dividiu o território em 15 lotes, repartidos e entregues a pessoas da pequena nobreza,

\footnotetext{
${ }^{3}$ Consoante Bourdieu (1989), o habitus relaciona-se à capacidade de uma determinada estrutura social ser incorporada pelos agentes por meio de disposições para sentir, pensar e agir, e pode ser entendido como um sistema de disposições invariáveis, duradouras, ou seja, como esquemas de percepção que são adquiridos pelos indivíduos durante sua trajetória de vida, ao interagirem nos diferentes campos como o político, econômico e jurídico, dentre outros.
} 
burocratas e comerciantes ligados à coroa, chamados, então, de capitães-donatários. A estes era assegurado o direito de doar sesmarias a terceiros (VIAL, 2003).

É importante salientar que a legislação sobre as terras do Brasil Colônia não tinha o mesmo sentido das leis modernas sobre a propriedade da terra, pois no início do período de colonização, a legislação agrária previa, basicamente, a distribuição de terras como única forma de acesso ao solo agrícola. Sendo assim, as Cartas de Doação de terras foram as primeiras formas jurídicas de legislação sobre a terra no que se refere ao domínio de particulares.

Em 1822, o sistema de concessões de sesmarias foi extinto através de uma Resolução do Príncipe Regente. O quadro fundiário se caracterizava por situações jurídicas irregulares e extravagantes, inexistindo uma legislação agrária. Até essa data, com exceção das doadas em sesmarias, todas as terras brasileiras faziam parte da Coroa Portuguesa. Todavia, de acordo com Stefanini (1978, p.50), tratavase de um

[...] período de abandono jurídico, de abdicação legal das responsabilidades fundiárias. Não se tinha acesso algum à propriedade de direito, supervindo uma vacância legislativa no que tange à matéria de alienações de terras públicas, bem como à normatividade do processo de transladação do patrimônio público para o particular e suas formas de aquisição, abrindo-se, assim as portas à livre ocupação de terras.

A partir de1822, tem início, no Brasil, o regime de posse ${ }^{4}$, isto é, a terra passou a ser ocupada por aquele que a explora e ergue benfeitorias. A Constituição Imperial de 1824, em seu artigo 179, instituiu o direito de propriedade garantido na sua plenitude, assim como a desapropriação por utilidade pública, mediante prévia indenização. Entrementes, apesar de extinto o regime de sesmarias, seus efeitos perduraram até $o$ advento da Lei $n^{\circ} 601$ de 1850, quando se estabelece uma nova plataforma jurídica conhecida como "Lei de Terras". Trata-se de um grande marco na medida em que tinha como escopo delimitar o que era de domínio particular e o que era, ou poderia ser, de domínio público. Todavia, estabelece também que a única forma de acesso ulterior à terra era comprando-a do governo, o qual fazia a mediação entre o domínio público e o proprietário individual.

De acordo com Peters (2009), o ano de 1850 pode ser considerado um divisor de águas no ordenamento jurídico brasileiro e na própria história territorial do país. Além da Lei de Terras, diversas leis foram editadas, como o Código Comercial Brasileiro, Lei 556 de 25 de junho de 1850, que continua vigente em parte até os dias atuais, e a Lei Eusébio de Queiroz, que foi uma modificação na legislação escravista brasileira, sendo considerada um dos primeiros passos para que fosse abolida a escravatura do Brasil. Entrementes, a Lei de Terras foi objeto de muitas críticas, com reflexos na história política e social, pois é considerada por muitos a raiz da luta pela terra e da desigualdade. Consoante Peters (2009, p.32):

A formação social e política do Estado brasileiro, é resultante da disputa de forças entre os donos da terra que defendiam ardentemente o privatismo e assim criavam os obstáculos ao desenvolvimento do poder público do Estado e a qualquer forma de intervenção deste na "questão da terra".

\footnotetext{
${ }^{4}$ Com a proibição da concessão de sesmarias, entre os anos de 1822 e 1850 (quando foi criada a Lei de Terras), a única forma de acesso legal à terra era a posse.
} 
A Constituição de 1891 reafirmou a plenitude do direito de propriedade ${ }^{5}$. A exceção a essa intangibilidade é a desapropriação por necessidade ou utilidade pública, mediante prévio pagamento (art. 72). Todavia, há que se considerar que o Código Civil brasileiro de 1916, no artigo 524, assegurava ao proprietário o direito de usar, gozar e dispor da coisa, bem como reavê-la do poder de quem injustamente as possuísse. Aqui se verifica que a segurança jurídica do proprietário da terra era inabalável. Ainda, de acordo com esse código, não se aceitava mais a reavaliação das sesmarias e também não era mais possível a legitimação de posse. Entretanto, era possível a aquisição de terras através do usucapião.

$\mathrm{Na}$ Constituição de 1934 pode-se dizer que o Brasil trouxe à discussão, pela primeira vez, a questão relativa à função social da propriedade, ainda de forma tímida. De acordo com o artigo 113, garantia-se o direito de propriedade, desde que o mesmo não fosse exercido contra o interesse social ou coletivo. Com o advento desse instrumento, ficou claro que o proprietário teria que enxergar para além de seus próprios interesses econômicos.

A referida Carta Política inaugura uma nova fase na história política brasileira, dado que foi a primeira Constituição que colocou o interesse social ou coletivo, dando uma nova roupagem ao direito de propriedade, que não aparece mais blindado pelo absolutismo enraizado que predominava até então.

A promulgação do Estatuto da Terra (Lei 4504, de 30/11/64) visava originalmente a viabilizar o acesso à terra para quem não a possuía, sendo visto como um dos mais importantes documentos jurídicos que embasam, legitimam e corroboram a luta pela terra no Brasil (VIAL, 2003). Não obstante, como indica a mesma fonte, o Ato Institucional $n^{\circ} 5$, de 13.12.68, teve reflexos nos mais diversos segmentos, inclusive na política agrária, em que o acesso à propriedade da terra só seria possível se os proprietários defendessem a integridade da Nação e a segurança nacional. Em pleno regime militar, esse ato institucional era mais um instrumento de cerceamento de direitos civis.

A década de 1980 trouxe a abertura democrática, tendo como marco crucial a promulgação da Constituição Federal de 1988 (doravante chamada CF), a qual foi concebida em um período de abertura política, redemocratização e de protestos em defesa dos direitos elementares do cidadão. Através do artigo 5ํ, em seus incisos XXII e XXIII da CF, foi reafirmado o direito de propriedade, bem como a necessidade de que a propriedade atenda a sua função social.

A inserção no ordenamento jurídico do princípio da função social delimitou os atributos e componentes integrantes do direito de propriedade, acarretando, na lei civil, a finalidade social da propriedade. Sendo assim, infere-se que a história da ocupação, conquista e posse da terra é a história da própria evolução social da sociedade brasileira, sendo que em cada etapa dessa evolução, novas formas de apropriação da terra foram surgindo.

\footnotetext{
${ }^{5}$ Não se pode menosprezar a importância que assume a propriedade da terra do ponto de vista político, sobretudo quando o simples ato de votar e de ser votado era exclusivo para os que dispusessem dessa condição.
} 


\title{
3. A FUNÇÃO SOCIAL DA TERRA
}

Foi com o advento do Estatuto da Terra que se definiu pela primeira vez quando a propriedade da terra cumpre a função social. De acordo com o artigo $2^{\circ}$, inciso $1^{\circ}$, isso ocorre quando simultaneamente ela:
a) favorece o bem-estar dos proprietários e dos trabalhadores que nela labutam, assim como de suas famílias;
b) mantém níveis satisfatórios de produtividade;
c) assegura a conservação dos recursos naturais;
d) observa as disposições legais que regulam as justas
relações de trabalho entre os que a possuem e a cultivam.

Apesar de já ter sido abordada nas outras constituições, a função social da terra só foi consagrada (como cláusula pétrea) na CF de 1988. Nesse contexto, as modificações sofridas na visão que se tinha do direito de propriedade evidenciaram que a mesma não pode ser regulada apenas pelo Direito Privado. Os interesses coletivos fizeram com que ela fosse abrangida pelo Direito Público, passando a ser regulada também pelo Direito Constitucional.

$\mathrm{O}$ artigo $5^{\circ}$ garantiu o direito de propriedade, desde que seja atendida a sua função social. Desse modo, a propriedade não existe isoladamente, visto que um dos elementos que a definem é o cumprimento da função social. Já o artigo 170 da Carta Magna inseriu essa função como um dos princípios da ordem econômica. Por outra parte, o Novo Código Civil Brasileiro de 2002 (Lei 10.406/02), diferentemente do Código Civil de 1916, em seu artigo 1228, adverte que:

\begin{abstract}
O direito de propriedade deve ser exercido em consonância com as suas finalidades econômicas e sociais e de modo que sejam preservados, de conformidade com o estabelecido em lei especial, a flora, a fauna, as belezas naturais, o equilíbrio ecológico e o patrimônio histórico e artístico, bem como evitada a poluição do ar e das águas.
\end{abstract}

Todavia, é no artigo 186 da CF que se vê definido que a função social da propriedade é cumprida quando essa atende, simultaneamente, e segundo critérios e graus de exigência estabelecidos em lei, aos seguintes requisitos:

\footnotetext{
I - aproveitamento racional e adequado;

II - utilização adequada dos recursos naturais disponíveis e preservação do meio ambiente;

III - observância das disposições que regulam as relações de trabalho;

IV - exploração que favoreça o bem-estar dos proprietários e trabalhadores.
}

Convém ressaltar que é imprescindível o cumprimento simultâneo de todos os requisitos para que se considere atendida sua função social. De acordo com o artigo 184 da CF, o não cumprimento da função social pela propriedade, acarreta não só uma tributação excessiva para o imóvel, como também a possibilidade de desapropriação para fins de reforma agrária.

Por outro lado, ao se explorar a terra, há que se ter a consciência de que deverão ser respeitados os limites do ecossistema onde se exerce a atividade. Além 
disso, a conservação dos recursos naturais é de interesse de todos, mas há outros aspectos a serem levados em conta nessa discussão, caso se tenha em mente que

[...] a questão ambiental deve ser pensada a partir de um contexto global, dado que conservação dos recursos naturais finitos é de interesse da comunidade como um todo. É o que nos mostra a noção de "desenvolvimento sustentável", que é aquele que atende às necessidades do presente, sem comprometer as necessidades das futuras gerações (ARAÚJO, 1998, p.86;aspas no original).

Sendo assim, admite-se que, no Brasil, o cumprimento da função social da terra é uma restrição geral e abstrata, constitucional e integrante do conceito de direito de propriedade, de forma que este se dirija não somente à satisfação dos interesses do proprietário, mas aos interesses da sociedade como um todo (BORGES, 2005). Com efeito, a função social tornou-se um princípio ético jurídico dirigido à sistematização da propriedade privada, recaindo no próprio conteúdo do direito de propriedade, dando-lhe, inclusive, um novo conceito.

A partir de então, a propriedade passa a ser vista como um elemento de transformação social que passa de um conteúdo extremamente individualista a um caráter muito mais social, submetendo-se, cada vez mais, aos interesses da coletividade.

\section{FUNÇÃO AMBIENTAL}

Historicamente, desde os primórdios da civilização, o homem já se preocupava com a salvaguarda e a conservação de seus recursos mais preciosos. Entre esses recursos, a natureza em todas as suas expressões, incluindo a terra, a água e as fontes de energia e de riqueza. Disciplinar o uso desses bens enseja o surgimento de convenções, acordos e leis ambientais.

No caso brasileiro, apenas na década de 1980 é que o ordenamento jurídico recepcionou efetivamente o discurso ambiental, deixando-se de trabalhar com tais questões de forma isolada e setorizada, passando a tratar o meio ambiente de forma integral e dinâmica, em que todos dependem uns dos outros e tudo influencia tudo. Em que pese o fato de já existirem normas ambientais importantes, foi a Constituição Federal de 1988, em seu artigo 225, que consagrou o meio ambiente ecologicamente equilibrado como um direito de todos, considerando-o como bem de uso comum do povo e essencial à qualidade de vida da população, impondo ao Poder Público e à coletividade o dever de defendê-lo e preservá-lo para as presentes e futuras gerações (PETERS, 2009).

Nos dias atuais, a propriedade, além de cumprir sua função social, tem que adequar-se às novas exigências ligadas à preservação do meio ambiente. $O$ artigo 186 da CF, - ao estabelecer em seu inciso II que a propriedade rural cumpre a sua função social quando ela atende, entre outros requisitos, à preservação do meio ambiente - impôs ao proprietário rural o dever de exercer o seu direito de propriedade em conformidade com a preservação da qualidade ambiental. De acordo com Peters (2009), a função ambiental é vista como um desdobramento lógico e inafastável da função social. Apesar de ter certa autonomia científica de tratamento, a função ambiental não pode ser vista apenas como uma simples dimensão da função social, pois é conteúdo integrante de um instituto maior, que é o direito de propriedade. 
Os deveres jurídicos do proprietário nem sempre serão os mesmos, variando conforme a natureza do objeto sobre o qual irá recair o direito de propriedade. Sendo assim, poderá não haver apenas uma função ambiental da propriedade, mas várias funções ambientais.

Todavia, no novo Código Civil consta que:

O proprietário tem a faculdade de usar, gozar e dispor da coisa, e o direito de reavê-la de quem injustamente a possua ou detenha.

$\S 1^{\circ} \mathrm{O}$ direito de propriedade deve ser exercido em consonância com as suas finalidades econômicas e sociais e de modo que sejam preservados, de conformidade com o estabelecido em lei especial, a flora, a fauna, as belezas naturais, o equilíbrio ecológico e o patrimônio histórico e artístico, bem como evitada a poluição do ar e das águas.

A conclusão a que se chega com a leitura desse parágrafo, é que o Código Civil de 2002, diferentemente do Código Civil de 1916, além de condicionar o exercício do direito de propriedade ao cumprimento da função social, condicionou-o também ao cumprimento da função ambiental. Para o objeto deste artigo importa advertir que:

Se a propriedade, sendo urbana ou rural, que possua qualquer recurso natural em seu interior o preservar, conforme legislação em vigor, estará atendendo um de seus requisitos na função social, qual seja, manter-se com o polo de equilíbrio ambiental dentro de um micro ou macroecossistema regional, atendendo assim, não somente aos interesses de seu proprietário, mas de toda a coletividade local. Se, ao descumprir a legislação em vigor, tiver seus recursos naturais degradados, estará obviamente descumprindo sua função social (CARADORI 2009, p.28).

É evidente que o direito de propriedade deve ser preservado, garantindo-se ao proprietário as faculdades de usar, gozar e dispor da coisa. Entretanto, é importante destacar que esse direito não pode se sobrepor às questões de interesse comum, como é precisamente o caso das ambientais. É possível utilizar a propriedade, mesmo que haja interferências nas questões de caráter ambiental, desde que haja a obediência às normas legais atinentes.

Vê-se, portanto, que o sistema legislativo do país se desenvolveu em direção a um amplo conjunto de normas que, se por um lado mostram-se rigorosas e bastante abrangentes, por outro, contêm aspectos de flexibilidade que indicam a preocupação em conciliar a proteção do meio ambiente e as necessidades do desenvolvimento econômico.

Deve-se ter em mente que o homem não tem o poder de destruir, quando se utiliza da sua capacidade de produzir na obtenção de bens materiais. Entrementes, se por um lado o sistema jurídico passou a garantir e assegurar a propriedade privada, por outro, passou a ser pressionado, cada vez mais, no sentido de que seja reconhecida uma função não apenas jurídica, mas também social e ambiental da terra. 


\subsection{Os espaços territoriais especialmente protegidos}

Com o surgimento da CF, o entendimento que muitos autores têm acerca dos Espaços Territoriais Protegidos, mencionados no artigo 225, é de que eles são considerados como um grupo ao qual pertencem todas as modalidades específicas de áreas de proteção, quais sejam: as Áreas de Preservação Permanente, Reserva Legal, Territórios Indígenas, Áreas de Zoneamento Ambiental e Unidades de Conservação. A Lei 9.985/2000 instituiu o Sistema Nacional de Unidades de Conservação da Natureza (SISNUC), tornando mais fácil a compreensão dos regimes e das classes de espaços territoriais especialmente protegidos. Do ponto de vista de Borges, são eles o gênero de que as unidades de conservação são as espécies.

\section{2. Áreas de preservação permanente}

O artigo $1^{\circ}$, caput, do Antigo Código Florestal estatuiu que:

As florestas existentes no território nacional e as demais formas de vegetação, reconhecidas de utilidades às terras que revestem, são bens de interesse comum a todos os habitantes do País, exercendo-se os direitos de propriedade com as limitações que a legislação em geral e especialmente esta Lei estabelecem.

O que se evidencia aqui é que o direito de propriedade poderá sofrer limitações para que a função ambiental possa ser cumprida. O marco legal pressupõe o intuito de preservar os recursos hídricos, a paisagem, a estabilidade geológica, a biodiversidade e o fluxo gênico de fauna e flora, bem como proteger o solo e assegurar o bem-estar das populações humanas.

É importante mencionar que a criação de uma APP, tanto por força de lei como por ato do poder público, acarreta uma limitação administrativa, restringindo, portanto, o exercício livre e pleno do direito de propriedade, decorrente do poder de polícia ${ }^{6}$ afeto à Administração Pública.

\subsection{Alterações do Código Florestal}

Durante a elaboração deste estudo, encontravam-se em discussão no Congresso Nacional vários projetos de reformulação do Código Florestal (Lei 4.771/65), gerando um embate entre distintas visões sobre a proteção de florestas e o desenvolvimento. Esse tipo de enfrentamento mostra uma das interfaces de um intenso campo de disputas políticas.

Um fato que exacerbou ainda mais esse conflito foi a edição da Medida Provisória 1.511/1996, que acarretou alterações substanciais no Código Florestal e que hoje, com o conteúdo bastante estendido, vigora na forma da Medida Provisória 2.166-67/2001. Em janeiro de 2010 existiam 36 projetos tramitando na Câmara dos Deputados com a finalidade de alterar, de alguma forma, o estatuído no Código Florestal (GANEM, ARAÚJO, 2010).

\footnotetext{
${ }^{6}$ Para Meirelles (2005, p.131), "Poder de polícia é a faculdade de que dispõe a Administração Pública para condicionar e restringir o uso e gozo de bens, atividades e direitos individuais, em benefício da coletividade ou do próprio Estado". Em linguagem menos técnica, pode-se dizer que o poder de polícia é o mecanismo de frenagem de que dispõe a Administração Pública para conter os abusos do direito individual.
} 
Mais adiante, outro acontecimento que reacendeu ainda mais esse embate e estimulou também diversas iniciativas objetivando alterações no Código Florestal foi o Decreto $n^{\circ} 6.514$, de 22 de julho de 2008, que regulamentou a Lei dos Crimes Ambientais (Lei $n^{\circ}$ 9.605, de 12 de fevereiro de 1998), dispondo sobre as infrações e sanções administrativas ao meio ambiente, estabelecendo o processo administrativo federal para apuração dessas infrações, além de outras providências.

Depois de passar pelas duas casas legislativas, no final do mês de maio de 2012, a presidenta da República vetou 12 artigos e fez 32 modificações no Projeto do Código Florestal. Para que o país não ficasse sem uma legislação ambiental, as alterações foram encaminhadas pelo governo ao Congresso, por meio da Medida Provisória $n^{\circ} 571 / 2012$, convertida na Lei 12.727, de 17 de outubro de 2012. Os embates no legislativo só fazem confirmar a profundidade dos enfrentamentos e a complexidade dos argumentos esgrimidos por diversos setores da sociedade.

\section{METODOLOGIA}

Como já foi mencionado introdutoriamente e tendo em vista que foi feita um pesquisa qualitativa, que tem como enfoque a Teoria das Representações Sociais, foram realizadas onze (11) entrevistas individuais semi-estruturadas.

A pesquisa não foi feita em um meio social específico, o que fez com que o problema da seleção dos entrevistados tenha se tornado mais complexo, tendo em vista que o assunto tem relevância em distintos contextos sócio-políticos. Sendo assim, foi necessário que se definisse quais os ambientes relevantes onde poderia ser feita a seleção dos entrevistados (BAUER; GASKELL, 2003).

Entre os entrevistados constam atores sociais de diversos segmentos de Pelotas e região, a saber: representantes da Associação Rural; Sindicato Rural; Sindicato dos Trabalhadores Rurais; Escritório local do Instituto Brasileiro do Meio Ambiente e dos Recursos Naturais Renováveis (IBAMA); Escritório local da Fundação Estadual de Proteção Ambiental Henrique Luiz Roessler (FEPAM); Escritório local da Secretaria Estadual do Meio Ambiente (SEMA); Secretaria Municipal de Qualidade ambiental (SQA); Secretaria de Desenvolvimento Rural (SDR); Escritório local da Empresa Brasileira de Extensão Rural (EMATER); Cooperativa Sul-ecológica de Agricultores Familiares Ltda. e Promotoria de Justiça Especializada de Pelotas. Após as entrevistas, realizadas entre março de 2010 e fevereiro de 2011 no município de Pelotas/RS, o próximo passo foi a transcrição e a análise das mesmas, com o olhar atento às visões de mundo dos atores sobre os aspectos discutidos anteriormente acerca da dimensão social e ambiental da terra. Nessa abordagem, utiliza-se as representações sociais como instrumento de interpretação.

\section{REPRESENTAÇÕES SOCIAIS EM DISCUSSÃO}

A análise do conteúdo $^{7}$ das entrevistas ${ }^{8}$ buscou desvendar, fundamentalmente, não só como se apresentam as representações sociais dos

\footnotetext{
${ }^{7}$ Utiliza-se aqui uma combinação entre a Teoria das Representações Sociais de Serge Moscovici e o método de análise de conteúdo, embasado pela teoria de Laurence Bardin (1977). Devido ao fato de que foi utilizado um método de abordagem qualitativo, foi analisado um pequeno número de informações complexas e pormenorizadas que tiveram como base a presença ou ausência de uma característica ou o modo como através do qual os elementos do discurso articulam-se uns com os outros. Sendo assim, além da frequência dos diferentes juízos, também foi calculada a sua intensidade e direção.

${ }^{8}$ As entrevistas foram realizadas no período compreendido entre março de 2010 e fevereiro de 2011, no município de Pelotas/RS.
} 
atores sociais do município de Pelotas sobre o uso dos recursos naturais, bem como indagar acerca do conflito existente entre os interesses dos produtores, suas práticas e percepções sobre a propriedade e uso dos recursos produtivos, e por outra parte, o esforço crescente de amplos setores da sociedade em preservar a integridade dos ecossistemas.

De um modo geral as representações sociais ou coletivas devem ser entendidas como processos ou fenômenos mentais compartilhados, através dos quais as pessoas organizam suas vidas. Vale dizer que é na obra fundacional da Sociologia moderna de Ėmile Durkheim (1895/1968) que se encontram as primeiras alusões a esse conceito, mormente na distinção que ele estabelece entre o que sejam representações 'individuais' e representações 'coletivas'. Todavia, como adverte Duveen (2010, p.13), o esforço para erigir a Sociologia como uma ciência autônoma fez com que Durkheim propusesse uma separação radical entre essas duas modalidades de representações, assumindo que as primeiras deveriam ser o campo da Psicologia, enquanto as últimas conformariam o objeto de Sociologia. Concretamente, pode-se dizer que as representações sociais governam as escolhas e as visões dos indivíduos, do ponto de vista valorativo. Observa-se como se apresenta a questão do ponto de vista da realidade investigada.

Tal como se analisou anteriormente, a evolução do direito de propriedade experimentou mudanças substanciais através do tempo. Mas é preciso considerar também as transformações operadas no plano das representações sociais dos atores com relação ao uso e posse dos recursos naturais. Pode-se constatar a preocupação de que a propriedade seja enxergada na sua totalidade através da fala do representante do Sindicato dos Trabalhadores Rurais de Pelotas:

Às vezes, aquela ânsia, aquela intranquilidade do produtor, ela é muito acentuada, então aí que começa as coisas. Quer dizer, tem uma intranquilidade, uma coisa puxa a outra, tu tá falando em meio ambiente, mas a nossa propriedade ela é um todo, não é só meio ambiente (informação verbal ${ }^{9}$ ).

A função ambiental passa a ser vista não apenas como uma dimensão que deve ser levada em consideração no exercício do direito de propriedade, dado que ela faz parte de uma estrutura muito mais ampla e complexa, a qual precisa ser observada na sua totalidade, como já foi mencionado no instituto da função social da propriedade.

Desta forma, evolui-se de uma concepção extremamente absoluta e individualista do direito de propriedade para uma concepção mais relativizada e voltada aos anseios da coletividade, o que pode ser corroborado através das palavras do representante da Promotoria Pública:

O que se tem feito, o que se debate hoje? O código florestal impede alegação de pleno exercício do direito de propriedade, não existe mais, a constituição revogou. Não tem mais essa de que eu faço o que eu quero. Tu fazes o que tu queres, respeitados aqueles limites que a constituição impõe, inclusive o meio ambiente (informação verbal ${ }^{10}$ ).

\footnotetext{
${ }^{9}$ Informação fornecida pelo representante do Sindicato dos Trabalhadores Rurais de Pelotas, em entrevista concedida no município de Pelotas, Abr/2010.

${ }^{10}$ Informação fornecida pelo representante da Promotoria, em entrevista concedida no município de Pelotas, Jun/2010.
} 
O nosso sistema jurídico, ao garantir e assegurar o regime da propriedade privada, exigiu, em contrapartida, que o proprietário cumprisse a função social e ambiental da propriedade da terra. Essa preocupação vem ocorrendo e pode ser evidenciada pela pesquisa com veemência, na fala do representante da Cooperativa Sul Ecológica de Agricultores Familiares Ltda.:

A gente não trabalha só a questão da produção. A gente trabalha o bem-estar da pessoa, dos animais, do meio ambiente. Então, são três coisas basicamente que a gente não pode se esquecer. É o bem-estar das pessoas, o agricultor tem que se sentir bem onde ele trabalha, ele e não pode estar, por isso que eu acho, e nada contra quem usa veneno e tal, eu acho que uma pessoa com todos aqueles equipamentos, máscara, macacão e não sei o que mais, em um dia de sol de $40^{\circ}$, mais o cheiro que aquele veneno tem, e eu acho que a pessoa não se sente bem lá dentro. Posso até estar enganado. Aí tu começa a ver que ele não só mata aquele inseto que está matando o que está destruindo a planta dele, ele tá matando os inimigos naturais também. Isso vai trazer um desequilíbrio para a natureza toda, os pássaros e daí por diante, os animais que eu acho que também tem o direito de ter uma vida digna, a gente trabalha isso também, e depois o consumidor final, a gente acha que também este merece uma comida saudável (informação verbal ${ }^{11}$ ).

Como já foi evidenciado, a propriedade é um direito garantido constitucionalmente, cujo exercício é condicionado ao cumprimento da função social. Todavia, há problemas atinentes ao exercício desse direito, os quais foram identificados na tomada dos mais diversos pontos de vista. Os principais problemas identificados foram a enorme burocracia do Estado na concessão de licenças e autorizações para viabilização e implantação dos empreendimentos e a injustiça pela qual está passando o usuário da terra, quando é considerado, muitas vezes, como o grande responsável pelos problemas ambientais.

Esse sentimento pode ser verificado na fala do representante do Sindicato dos Trabalhadores Rurais de Pelotas, quando remete a discussão para o debate acerca do antagonismo campo-cidade:

Quem é que polui mais? O meio urbano ou o meio rural? Quer dizer, nós temos que preservar, nós, agricultores, temos que preservar e somos punidos. Entra em qualquer cidade, aqui em Pelotas, vai aqui na vila, olha esses córregos que tem ali, eu fico com pena, eu fico triste, porque eu sou uma pessoa que também tenho descendentes aqui, que vão ter que usar este ambiente. Mas tem lugares aí, umas sangas aí, uns arroiozinhos aí, que atravessam essas vilas aí, dá pena de olhar, dá vontade de chorar, não é mais água, sim, mas e aí, ninguém faz nada, ah mas lá a vaca não pode beber água do arroio porque ela pode estercar dentro da água e vir para, vê se pode, agora, não é aquela vaca lá que faz aquilo ali que vem aqui encher o nosso Laranjal e as praias de

\footnotetext{
${ }^{11}$ Informação fornecida pelo representante da Cooperativa Sul Ecológica de Agricultores Familiares Ltda., em entrevista concedida em março de 2010.
} 
improbabilidades (Representante do Sindicato dos Trabalhadores Rurais de Pelotas) (informação verbal1 ${ }^{12}$ ).

Como já foi mencionado, apesar de já existirem, há muitos anos, normas ambientais importantes, só em tempos relativamente recentes o discurso ambiental foi incorporado ao ordenamento jurídico, pois foi apenas na Constituição Federal de 1988 que o meio ambiente foi reconhecido e consagrado como um direito de todos e um bem difuso de uso comum. A importância atual da adoção desse discurso ambiental pela nossa Carta Maior e seu impacto sobre consciências e habitus pode ser notada, neste trabalho, através da fala de alguns dos entrevistados. A interpretação do representante do IBAMA resgata essa trajetória nos seguintes termos:

[...] nos anos 80 , já se iniciava alguma coisa sobre preservação ambiental, sobre esses órgãos vinculados à preservação ambiental. Então, se tinha um início disso. Mas, no início dos anos 90 , é que iniciou, até mesmo com essa preocupação em criação do Ibama, e esses conceitos ambientais, que muitos ecologistas levantaram, em razão disso que se criou uma nova mentalidade. Então se tem, através do Ibama e através dos órgãos judiciários, promotoria pública e juízes, tudo com conceitos de preservação ambiental e cumprimento de legislação ambiental ao rigor. O rigor no cumprimento destas questões ambientais. Então, o brasileiro, a pessoa sofre muito, penas, muita repressão, e isso ajuda muito a criar um conceito de preservação ecológica. Muitas vezes as pessoas com formação já mais antiga não entende. Compreende que deva fazer, mas não entende por quê. Porque não tem aquele conhecimento de por que preservar. Por que eles pensam assim? Porque a vida de um animal tem maior valor que a vida de um ser humano? Eles têm essa ideia errada. Eles não entendem que a finalidade é de preservar um animal até em função da vida humana na terra, no planeta. Uma árvore vale mais do que uma pessoa. Muitas pessoas pensam assim. Têm uma ideia errada (informação verbal ${ }^{13}$ ).

Vê-se que o agente do órgão ambiental, mesmo não vinculado aos produtores rurais, expressa sua percepção mencionando as antigas práticas no uso da propriedade quanto à estranheza e resistência, mesmo que psicológica, às imposições sobre uma nova ordem de valoração das coisas, na qual um animal ou até uma árvore deveriam ser tratados e preservados prioritariamente frente à sobrevivência do homem. Essa mentalidade está fortemente enraizada, sobretudo entre as pessoas mais velhas, cujas concepções e habitus acham-se cristalizadas e distantes da evolução gradual dos debates sociais:

$\mathrm{Na}$ questão atinente ao direito material ambiental é uma legislação nova, pesada que precisa ser amadurecida por todos, então não posso achar que um, alguém que mora no meio rural, que não passou pelas escolas, tenha perfeita compreensão do que é a constituição e do que é direito ambiental. Então, aí há um choque porque a nós, da qualidade ambiental, cabe garantir a sustentabilidade do meio ambiente,

\footnotetext{
12 Informação fornecida pelo representante do Sindicato dos Trabalhadores Rurais de Pelotas, em entrevista concedida em abril de 2010.

${ }^{13}$ Informação fornecida pelo representante do IBAMA, em entrevista concedida em fevereiro de 2011.
} 
garantir o meio ambiente equilibrado das presentes e futuras gerações, respeitar todos os procedimentos que são exigidos por uma república democrática, em confronto ainda com uma concepção de sociedade individualista que não enxerga o outro, sendo que a vocação do direito ambiental é enxergar o terceiro, o meio ambiente em si, não, e garantir a sua tutela (Representante da Secretaria de Qualidade Ambiental). (informação verbal ${ }^{14}$ ).

O que se pode extrair dessas falas é de que não existe, ainda, entre esses atores, uma completa assimilação do espírito e da real importância da legislação ambiental, o que permite a permanência de um conflito imanente entre os interesses e as prioridades (individuais e coletivas), determinado pela tradição, pela cultura, pelo consenso grupal e pelo isolamento.

Por outro lado, de acordo com a visão do representante da Secretaria Estadual do Meio Ambiente, o que há é uma percepção de um conflito derivado da lenta assimilação cultural:

A falta de informação ainda é muito grande, por isso que existe aquela percepção do conflito, do conflito ou do desajuste, por que o processo da agricultura é um processo cultural, que foi adquirido ao longo dos tempos. O procedimento de proteção ambiental e da biodiversidade é um processo que ainda está muito recente, desde a constituição de 1988 para cá. Isso, para muitas pessoas, ainda não entrou na cabeça. Como é que eu não vou poder fazer uma atividade? Fiz a vida inteira. Existe aquela forte tradição da herança cultural, então, é muito mais fácil tu entenderes isso na agricultura, e tu teres mais adeptos a esse lado, do que ter adeptos, por exemplo, a práticas de manejo integrado, de manejo de agroecologia, manejo de produção, que tu aproveites mais os recursos naturais, não agridas com agrotóxicos, ou com práticas devastadores, com máquinas mal dimensionadas, utilização de sementes não apropriadas, então, tem uma série de coisas, aí poderias trabalhar mais harmoniosamente onde há natureza, plantio direto, conservação do solo, não deixar vir a erosão, todos esses são os aspectos, que ainda não se incorporaram na herança cultural minha, nem tua (informação verbal ${ }^{15}$ ).

Esse entendimento do entrevistado indica a influência exercida pela herança cultural, por força daquilo que foi sendo transmitido, de geração a geração, do ponto de vista de práticas adotadas pelos produtores. Conforme adverte Bourdieu (1989, 1990), isso se deve à posição ocupada e ao habitus adquirido e incorporado pelos indivíduos ao longo de sua trajetória, parecendo contraditório quando o mesmo afirma que o processo da proteção ambiental "ainda está muito recente" e que "isso, para muitas pessoas ainda não entrou na cabeça". Sendo assim, confirma-se que, muitas vezes, as ações dos produtores rurais são orientadas ou coagidas e só se tornam rotineiras pelo peso do habitus.

Por outro lado, constatou-se o aparecimento, nas falas dos entrevistados, e com relativa frequência, de supostos desajustes entre a aplicação da legislação e a

\footnotetext{
${ }^{14}$ Informação fornecida pelo representante da Secretaria de Qualidade Ambiental, em entrevista concedida em junho de 2010.

${ }_{15}$ Informação fornecida pelo representante da Secretaria Estadual do Meio Ambiente, em entrevista concedida em abril de 2010.
} 
realidade do produtor. A grande maioria dos discursos expôs que existe, sim, um desajuste entre a legislação e a realidade do produtor. Na fala do Representante da Cooperativa Sul Ecológica de Agricultores Familiares, esse aspecto é claro:

Como já tinha falado, são pequenos ajustes na lei. No meu ponto de vista, eu acho que em partes ela é um pouco rígida. Se realmente tem uma nascente aqui e diz que tem que ter 20 $\mathrm{m}$ de cada lado, às vezes tem que ter um pouquinho de tolerância, tu tens $10 \mathrm{~m}$ aqui e podes ter $30 \mathrm{~m}$ aqui embaixo. Cada área é uma realidade diferente, cada agricultor é uma realidade diferente, então acho que este olhar aí, externo, tem que ter um pouco de formas, eu sei que é difícil isso, tu dares uma vantagem para um, para o outro não, e tal [...]. Eu acho que tem que haver uma adaptação. Cada área e cada região é diferente. Então, eu acho que não dá pode usar o mesmo modelo aqui do sul do R. G. do Sul, no Nordeste (Representante da Cooperativa Sul Ecológica de Agricultores Familiares) (informação verbal ${ }^{16}$ ).

Já se sabe que a dimensão ambiental é apenas um dos aspectos que devem ser levados em consideração para que o direito de propriedade seja exercido conforme as exigências constitucionais. Sendo assim, existem problemas referentes ao cumprimento da legislação, de forma que também seja cumprida a função ambiental da propriedade, os quais foram revelados na análise do conteúdo das entrevistas.

No município de Pelotas, evidenciou-se que os principais problemas enfrentados no cumprimento da legislação são os relativos às Áreas de Preservação Permanente e Reserva Legal, apesar de algumas falas de representantes dos órgãos de fiscalização negarem a ocorrência desses problemas.

Entrementes, apesar de ter ficado evidente a existência de tensões, a análise do conteúdo das entrevistas mostra certa convergência em relação ao futuro sobre as questões que envolvem a convivência entre o exercício pleno do direito de propriedade rural e a aplicação da legislação de meio ambiente, com vistas à sustentabilidade.

Com respeito à possibilidade de que ocorra uma conciliação ou harmonização entre, de um lado, os interesses dos produtores, práticas e representações sociais sobre a propriedade e recursos produtivos, e de outro, o esforço da sociedade em preservar a integridade dos ecossistemas, as percepções de grande parte dos entrevistados revelaram que essa convergência não só é possível, como já está acontecendo, fato que pode ser ilustrado na seguinte fala:

Acho que vamos chegar, não sei quando, não sei quando mas vamos ter que chegar neste nível aí. Acho que é possível compatibilizar, através do diálogo, não existe outra forma, e através da preponderância do valor vida sobre o valor econômico. [...] Tenho o teu sonho? Tenho. Vamos buscar? Vamos. Acho que vai acontecer? Vai. Vamos demorar? Vai. Não vai ser para mim, talvez seja para os meus filhos, talvez seja para os netos. Acho que eles vão encontrar coisa melhor. [...] Tem que mudar. Vai mudar. Não sei quando vai. Como é que eu vou chegar para meus filhos e dizer: olha aqui, isso aqui não tem solução. [...] Não, vai mudar. Vai, aos poucos, vai

\footnotetext{
${ }^{16}$ Informação fornecida pelo representante da Cooperativa Sul Ecológica de Agricultores Familiares, em entrevista realizada em março de 2010.
} 
mudar. Está mudando. Estamos melhor que há vinte anos atrás, estamos. [...] Vamos todos sobreviver, ou vamos todos naufragar? Não tem como ser diferente. Não acredito que possa ser diferente, não acredito que vamos piorar nas questões ambientais, acho que a tendência é a consciência ambiental, ela por si só vai mudar. Acho que nós caminhamos para isso. E precisamos ardentemente dos xiitas, ou dos ecoambientalistas, como é que se chamam os mais radicais? Eco - chatos. Os que chamam de ecochatos, eles são necessários. E com a chatice deles, eles nos chamam atenção. $\mathrm{E}$ só aí nós percebemos algumas coisas. Eu gosto do ecochato, eu gosto do consumidor chato, embora eu não seja chato e tal, ou talvez não me considere, mais eles é que fazem agente despertar, nós precisamos de alguns radicalismos, o radical sempre é necessário, não para destruir, mas para construir a partir dele (informação verbal ${ }^{17}$ ).

O Ministério Público, com sua participação na elucidação de conflitos nessa área, traz a valiosa expressão da experiência na lida com a diversidade de posições e de argumentos divergentes, chamando a atenção, com prioridade de valor, para a vida e para o fato de que o objetivo da conciliação é daqueles que, pela natureza e magnitude de interesses envolvidos, só se atinge através de complexos entendimentos os quais, entretanto, já vêm ocorrendo com bons resultados. Correse 0 risco de considerar que essa opinião traduziria o pensamento e as representações sociais da média da sociedade sobre os embates entre a legislação ambiental e o mundo rural, por força das peculiaridades da função pública que o Ministério Público exerce e por permitir uma ampla absorção das aspirações de todas as vertentes e de sua projeção, tanto no tempo como na variedade de locais e cenários de onde se originam os desajustes.

As percepções de todos os entrevistados, ao emitirem uma avaliação sobre a possibilidade de que ocorra uma conciliação e uma harmonização dos interesses foram exteriorizadas com um alto grau de convicção. Houve um predomínio e uma frequência maior nas opiniões positivas (favoráveis), que veem com otimismo a possibilidade de se conciliar os interesses individuais com os coletivos. Desta forma, as percepções dos atores sociais ouvidos expressam a realidade do setor agropecuário e um ambiente real, não obstante, regido por algumas incertezas. Tais representações sociais espelham, de fato, como bem ensinou Minayo (1995), categorias de pensamento pelos quais uma sociedade elabora, reelabora e expressa a sua realidade. A conciliação dos interesses, quando atingida, passa a exprimir a nova realidade dos atores sociais, conquistada pela exteriorização da contrariedade com as antigas atitudes.

\section{CONSIDERAÇÕES FINAIS}

Diante do exposto, percebe-se que o direito de propriedade sofreu e vem sofrendo inúmeras transformações no decorrer do tempo até os dias atuais. Ao conceito original de propriedade foram agregadas novas finalidades, a partir da necessidade de se atender a novos anseios que atravessam a sociedade, sobretudo por força do despertar de uma nova consciência em torno aos imperativos de justiça social e de uma gestão mais equânime e democrática das riquezas e oportunidades. Desta forma, as terras de domínio privado passaram a ter um comprometimento

\footnotetext{
${ }^{17}$ Informação fornecida pelo representante da Promotoria, em entrevista concedida em junho de 2010.
} 
muito maior com a nação como um todo, no que se refere à qualidade de vida de seus membros e à preservação dos recursos naturais para as presentes e futuras gerações.

A análise do conteúdo das entrevistas serviu para trazer à tona as representações sociais, ou seja, o juízo, a avaliação, e mais especificamente, a atitude dos atores sociais do município de Pelotas sobre o uso dos recursos naturais, levando-se em consideração a emergência de um novo marco jurídico que regula as atividades agropecuárias, em meio à crescente relevância assumida pelos objetivos conservacionistas e da sustentabilidade ambiental.

Ficou perceptível na pesquisa que ainda existem lacunas e dificuldades na compreensão e aceitação da legislação ambiental. Práticas que foram transmitidas de geração a geração tornam-se rotineiras. A ação do produtor e suas escolhas, de um modo geral, ainda são coagidas pelo habitus adquirido e incorporado ao longo de sua trajetória, muito embora seja evidente nessas ações, também, uma despreocupação com a degradação ambiental que pudesse estar sendo causada.

Em verdade, o que se pode deduzir é que não havia em épocas anteriores uma pressão conservacionista como nos dias atuais, e ainda, que esse habitus foi formado na ausência de legislação e regulamentos efetivos sobre a matéria, aliada à relativa distância de uma fiscalização mais efetiva e, também, do forte ativismo ambientalista que tomou uma dimensão inexistente há algumas décadas atrás. A percepção do risco, o reconhecimento acerca da gravidade do processo de câmbio climático e os grandes crimes ambientais, dentre outros fatores, contribuem para esse cenário de incertezas e de forte questionamento sobre suas causas.

Outra questão evidenciada na maioria dos depoimentos diz respeito ao desajuste que existe entre a aplicação da lei e a realidade do produtor, sendo um forte indício de que a legislação deva sofrer alterações. O presente estudo revelou a existência de tensões recorrentes, nem sempre explícitas, devido às diferentes percepções existentes sobre o uso dos recursos naturais em sua acepção absoluta e exclusiva, e a aceitação/submissão aos interesses coletivos ligados à preservação e aos imperativos da sustentabilidade.

Todavia, o momento presente sinaliza para uma convergência e concertação, muito mais do que para rupturas de maior calado. Percebe-se, destarte, um desejo dos atores sociais no sentido de que se atinja uma síntese de interesses, obtida através da adaptação da legislação ambiental e, também, das exigências da sustentabilidade, das práticas sociais e da formação, pelo diálogo constante entre as duas esferas - o individual e o coletivo - de novas posturas, teóricas e práticas, de convivência, com maior tolerância recíproca das próprias consciências. A simples construção de novas mentalidades e práticas que conduzam à predominância absoluta da preservação ambiental sobre a necessidade social do aproveitamento econômico nas propriedades rurais deverá engendrar um processo de readaptação que, evidentemente, não será no curtíssimo prazo.

Não se pretende esgotar a investigação sobre 0 universo de comportamentos, possibilidades e percepções dos atores sociais em geral. O mesmo há que ser dito com relação à esfera de atuação dos agentes públicos encarregados de comandar, executar, fiscalizar e fazer cumprir o conjunto de normas ambientais. Trata-se de um ponto de chegada, mas também de partida para futuros trabalhos sobre um tema atual e não menos controvertido. Não se extingue o processo permanente de evolução do pensamento e do próprio espírito do homem rural na sua atitude filosófica e social, como também a natureza objetiva e pragmática da questão quando trata das atenções que devem ser dadas à terra no dúplice sentido: 0 de provedora ainda não explorada em todas as suas potencialidades e, antes de tudo, o de "ninho, lar", ponto de ancoragem, 
sobrevivência e de desenvolvimento pessoal e coletivo, que deve ser protegido da depredação, para as presentes e as futuras gerações.

\section{REFERÊNCIAS}

ARAÚJO, L. E. B. de. O acesso à terra no Estado Democrático de Direito. Frederico Westephalen: URI,1998. 254p.

BARDIN, L. Análise de conteúdo. Lisboa, Portugal: Edições70.1997.222p.

BAUER, M. W.; GASKELL, G. (Ed.). Pesquisa qualitativa com texto, imagem e som. Petrópolis: Vozes, 2003.516p.

BORGES, R. C. B. Função ambiental da propriedade rural. In: Direito agrário na constituição. Rio de Janeiro: Forense, 2005. p.271-303.

BOURDIEU, P. Espaço social e poder simbólico. In: Coisas ditas. São Paulo: Brasiliense, 1990 p.149-168.

O poder simbólico. Lisboa: DIFEL, 1989. 315p.

BRASIL. Ato Institucional no 5, de 13.12.68. Disponível em: http://www.fpa.org.br. Acesso em 19 de março de 2015

Constituição Política do Império do Brazil, promulgada em 25 de março de 1824. Disponível em: http://www.presidencia.gov.br. Acesso em: 03.maio.2015.

\section{Constituição da República dos Estados Unidos do Brasil,} promulgada em 24 de fevereiro de 1891. Disponível em: http://www.presidencia.gov.br. Acesso em: 03.maio.2015.

Constituição da República dos Estados Unidos do Brasil, promulgada em 16 de julho de 1934. Disponível em: http://www.presidencia.gov.br. Acesso em: 03.maio 2015.

.Constituição Federal da República Federativa do Brasil, promulgada em 05 de outubro de 1988. Disponível em: http://www.presidencia.gov.br. Acesso em: 03.maio 2015.

Decreto $n^{\circ}$ 6.514,de 22 de julho de 2008. Dispõe sobre as infrações e sanções administrativas ao meio ambiente, estabelece o processo administrativo federal para apuração dessas infrações e dá outras providências. Disponível em: http://www.planalto.gov.br. Acesso em: 02 jul. 2015.

Lei $n \times 601$, de 18 de setembro de 1850. Dispõe sobre as terras devolutas do Império. Publicada na CLB de 1850. Disponível em: http://www.planalto.gov.br. Acesso em: 03 maio 2015.

Lei no 3.071, de 1ㅇ de janeiro de 1916. Institui o Código Civil dos Estados Unidos do Brasil. Diário Oficial da União, Rio de Janeiro, RJ, 5 jan.1916.Disponível em: http://www.planalto.gov.br. Acesso em: 03 maio 2015. 
Lei $\mathrm{n}$ - 4.504, de 30 de novembro de 1964. Dispõe sobre o Estatuto da Terra e dá outras providências. Diário Oficial da União, Brasília, DF, 31. nov.1964. Disponível em: http://www.planalto.gov.br. Acesso em: 03 maio 2015.

Lei $\mathrm{n}^{\circ}$ 4.771, de 15 de setembro de 1965. Institui o novo Código Florestal. Diário Oficial da União, Brasília, DF, 16. set. 1965 e retificada em 28. Set.1965. Disponível em: http://www.planalto.gov.br. Acesso em: 03 maio 2015.

Lei no 9.985, de 18 julho de 2000. Regulamenta o art. 225, $\S 1^{\circ}$, incisos I, II, III e VII da Constituição Federal, institui o Sistema Nacional de Unidades de Conservação da Natureza e dá outras providências. Diário Oficial da União, Brasília, DF, 19. Jul.2000. Disponível em: http://www.planalto.gov.br. Acesso em: 03 maio 2015.

Lei no 10.406, de 10 de janeiro de 2002. Institui o Código Civil. Diário Oficial da União, Brasília, DF, 11. jan.2002 Disponível em: http://www.planalto.gov.br. Acesso em: 03 maio 2015.

Lei 12.727 de 17 de outubro de 2012. Altera a Lei $n^{\circ}$ 12.651, de 25 de maio de 2012, que dispõe sobre a proteção da vegetação nativa; altera as Leis $\mathrm{n}$ os 6.938 , de 31 de agosto de 1981, 9.393, de 19 de dezembro de 1996, e 11.428, de 22 de dezembro de 2006; e revoga as Leis $\mathrm{n}^{\text {os }} 4.771$, de 15 de setembro de 1965 , e 7.754, de 14 de abril de 1989, a Medida Provisória no 2.166-67, de 24 de agosto de 2001, o item 22 do inciso II do art. 167 da Lei no 6.015, de 31 de dezembro de 1973, e $0 \S 2^{\circ}$ do art. $4^{\circ}$ da Lei $n^{\circ} 12.651$, de 25 de maio de 2012.. Disponível em: http://www.planalto.gov.br. Acesso em: 09 maio 2015.

Medida Provisória $n^{\circ}$ 1.511/1996. Dá nova redação ao art. 44 da Lei $n^{\circ}$ 4.771 , de 15 de setembro de 1965, e dispõe sobre a proibição do incremento da conversão de áreas florestais em áreas agrícolas na região Norte e na parte Norte da região Centro-Oeste, e dá outras providências. Disponível em: http://www.planalto.gov.br. Acesso em: 19 março 2015.

Medida Provisória no 2.166-67, de 24 de agosto de 2001. Altera os arts. $1^{\circ}, 4^{\circ}, 14,16$ e 44, e acresce dispositivos à Lei $\mathrm{n}^{\circ}$ 4.771, de 15 de setembro de 1965, que institui o Código Florestal, bem como altera o art. 10 da Lei no 9.393, de 19 de dezembro de 1996, que dispõe sobre o Imposto sobre a Propriedade Territorial Rural - ITR, e dá outras providências. Disponível em: http://www.planalto.gov.br. Acesso em: 19 março 2015.

Medida Provisória $\mathrm{n}^{\circ}$ 517, de 25 de maio de 2012. Altera a Lei $\mathrm{n}^{0}$ 12.651, de 25 de maio de 2012, que dispõe sobre a proteção da vegetação nativa; altera as Leis $n^{\text {os }} 6.938$, de 31 de agosto de 1981, 9.393, de 19 de dezembro de 1996, e 11.428, de 22 de dezembro de 2006; revoga as Leis $n^{\text {os }} 4.771$, de 15 de setembro de 1965, e 7.754, de 14 de abril de 1989, e a Medida Provisória no 2.166 67, de 24 de agosto de 2001. Disponível em: http://www.planalto.gov.br. Acesso em: 05 agosto 2015.

CARADORI, R. C. O Código Florestal e a legislação extravagante: a teoria e a prática da proteção florestal. São Paulo: Atlas, 2009. 238p. 
DURKHEIM, È. As regras do método sociológico. 5 $5^{\mathrm{a}}$ Ed., São Paulo: Editora Nacional. 1968.

DUVEEN, G. Poder das ideias. In: MOSCOVICI, S. Representações sociais. Investigações em psicologia social, Petrópolis: Editora Vozes, p.7-28. 2010.

GANEM, R. S; ARAÚJO, S. M. V. G. Revisão do Código Florestal: análise dos projetos de lei em tramitação no Congresso Nacional. In: SILVA, S. T.; CUREAU, S.; LEUZINGER, M. D. (coord.) Código Florestal: desafios e perspectivas. São Paulo: Fiúza, 2010. p.376-401.

MEIRELLES, H. L. Direito administrativo brasileiro. São Paulo: Malheiros Editores, 2005. 808p.

MINAYO, M. C. S. O conceito de representações sociais dentro da sociologia clássica. In: GUARESCHI, P. A.; JOVCHELOVITCH, S. (org.) Textos em representações sociais. Petrópolis: Vozes, 1995. p. 89-111.

MOSCOVICI, S. Representações sociais. Petrópolis: Vozes, 2003. 404p.

PETERS, E. L. Meio ambiente e propriedade rural. Curitiba: Juruá, 2009. 192p.

STEFANINI, L. L. A propriedade no direito agrário. São Paulo: Revista dos Tribunais, 1978.300 p.

VIAL, S. R. M. Propriedade da terra: análise sociojurídica. Porto Alegre: Livraria do Advogado Editora, 2003. 279p. 